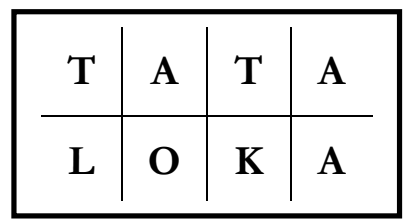

JuRnal Tata LoKa; Volume 13; Nomor 3; Agustus 2011 (C) 2011 Biro Penerbit Planologi UNDIP

\title{
Pengaruh Jalan Lingkungan Sebagai Ruang Interaksi Sosial Terhadap Lingkungan Permukiman Bungur, Jakarta Pusat
}

\author{
Influence of Residential Street as Social Interaction Space On Neighborhood Environment
}

\author{
Nany Yuliastuti dan Adinda Sekar Tanjung \\ Jurusan Perencanaan Wilayah dan Kota, Fakultas Teknik, Universitas Diponegoro \\ J1. Prof Soedharto, SH No. 1, Kampus Undip Tembalang, Semarang 50275 \\ E-mail:n.yuliastuti@undip.ac.id; adinda.s.t@gmail.com
}

\begin{abstract}
Abstrak: Jalan merupakan salah satu jaringan penting yang akan menghubungkan antar wilayah. Jalan adalah tempat untuk perdagangan dan pertukaran barang, bahkan untuk melakukan pekerjaan, terutama di negara-negara timur (Jacobs dalam Kiang et al, 2010:160). Jalan di Asia terus berkembang sebagai suatu jalan yang berbeda dengan jalan di Negara barat, yakni mencerminkan budaya Asia yang unik (Dayaratne dalam Kiang et al, 2010:63). Keunikan tersebut terlihat dari jalan yang digunakan sebagai ruang untuk menyelenggarakan festival tahunan, sebagai upacara keagamaan, acara pemakaman, sebagai pasar, sebagai zona penyangga antar kelompok ras,dll. Kegiatan yang terjadi di jalan tersebut pada akhirnya menambahkan fungsi lain pada jalan yakni sebagai ruang interaksi sosial. Jalan di Kelurahan Bungur, Jakarta Pusat digunakan oleh masyarakat sebagai ruang untuk saling bertukar pikiran, jual beli, tempat bermain anak, dan festival tahunan. Penelitian ini bertujuan menganalisis pengaruh fungsi jalan lingkungan dan gang sebagai ruang interaksi sosial terhadap permukiman Kelurahan Bungur. Adapun pendekatan penelitian ini adalah pendekatan kuantitatif dengan strategi penelitian survei dan metode analisis statistik deskriptif. Hasil penelitian menunjukkan bahwa jalan lingkungan di Kelurahan Bungur telah menjadi suatu ruang publik yang digunakan masyarakat untuk saling berinteraksi yang ditunjukkan oleh beragam aktivitasnya. Interaksi sosial tersebut telah menguatkan ikatan sosial masyarakat pada lingkungan permukiman tersebut.
\end{abstract}

Kata kunci: jalan lingkungan, gang, interaksi sosial, lingkungan permukiman

\begin{abstract}
Streets are one of important network that will connect between area. Streets are the stage for commerce and exchange of goods, even for doing work, especially in eastern countries (Jacobs in Kiang et al, 2010:160). Street of Asia have been and continue to evolve as distinct from those of the west, reflecting the unique Asian cultures (Dayaratne in Kiang et al, 2010:63). The unique can be looked from street that used for held community festival, held funeral, street market, and social activity space, etc. Residential street became public space that very useful for social interaction space (visible in daily activity and community festival). Activities that happen on the street eventually will add other functions on the street as a space of social interaction. Residential streets in the Bungur Sub District, Central Jakarta used by the public as a space for exchanging ideas, buying and selling, children's playground, and an annual festival. The aim of this research is to analyze influence residential street and alley function as social interaction space on neighborhood environment. However, research method that used in this final project is quantitative with survey research strategy and statistic descriptive as analysis method. The results showed that the residential streets in Bungur Sub District has become a public space that allows people to interact with each other (shown by a variety of activities). Social interaction has strengthened the social ties and realized a strong kinship in these neighborhood.
\end{abstract}

Keywords: residential streets, social interaction, neighborhood environment 


\section{Pendahuluan}

Kecamatan Senen merupakan bagian dari Kota Administrasi Jakarta Pusat yang memiliki potensi sebagai pusat perdagangan skala besar dan terletak di daerah kota inti. Kecamatan Senen terdiri dari 6 kelurahan dan salah satunya adalah Kelurahan Bungur. Kelurahan Bungur merupakan kawasan permukiman pusat kota yang memiliki karakteristik hunian padat dengan luasan perumahan sebesar 60,3 $\mathrm{Ha}$ dan luasan fasilitas umum 2,34 $\mathrm{Ha}$ (data Kelurahan Bungur 2010). Jumlah penduduknya adalah 16.204 jiwa dengan kepadatan 260 jiwa/ha (data Kelurahan Bungur tahun 2010).

Permukiman Kelurahan Bungur dapat dicapai dengan mudah karena pola jaringan jalannya yang grid dan permukimannya dikelilingi oleh jaringan jalan arteri primer, kolektor primer dan kolektor sekunder (Gambar 1). Ketiga jenis jaringan jalan tersebut dilalui oleh angkutan kota, sehingga mempermudah pergerakan masyarakat yang tidak memiliki kendaraan. permukiman ini memiliki sarana yang cukup lengkap, diantaranya 12 sarana peribadatan, 494 sarana perdagangan, 1 puskesmas, dan 14 sarana pendidikan. Dari segala fasilitas yang ada di Kelurahan Bungur, permukiman ini masih memiliki kekurangan dari segi ruang publik, khususnya tempat dimana masyarakat melakukan interaksi sosial antar sesama warga dan tempat anakanak bermain.

Ruang publik dapat berupa taman publik, lapangan, tempat peringatan, pasar, jalan, lapangan bermain, ruang terbuka masyarakat, jalur hijau, atrium, dan ruang terbuka di lingkungan bertetangga (Carr et al,1992: 79-84). Jumlah taman yang hanya 3 dan terletak di dua Rukun Warga (RW) membuat warga RW lainnya sulit untuk dapat mengakses ruang publik tersebut. Hal ini menjadi salah satu faktor bagi masyarakat untuk menyiasati ruang publik di lingkungan hunian dengan memanfaatkan jalan dan gang.

Masyarakat menggunakan jalan lingkungan dan gang sebagai ruang interaksi sosial. Sifat interaksi sosial yang terjadi di jalan dan gang tersebut berupa interaksi sosial yang berulang terus/ rutin dan teratur. Bentuk interaksi sosial tersebut antara lain warga yang mengobrol dengan tetangga, warga yang berjualan, warga yang mengadakan kegiatan perayaan tertentu, dll.

Jalan adalah tempat orang bertemu dan bersosialisasi, jalan menjadi tempat orang-orang untuk berada di luar, khususnya jika rumah mereka kecil. Jalan adalah tempat untuk perdagangan dan pertukaran barang bahkan untuk melakukan pekerjaan, terutama di negara-negara timur (Jacobs dalam Kiang et al, 2010:160). Jalan di Asia terus berkembang sebagai suatu jalan yang berbeda dengan jalan di Negara barat, yakni mencerminkan budaya Asia yang unik (Dayaratne dalam Kiang et al, 2010:63). Oleh karena itu, penelitian ini menjadi sangat menarik untuk diteliti karena fenomena di Kelurahan Bungur menjadi bagian dari karakateristik unik jalan - jalan di negara Asia.

Makna pengaruh fungsi jalan sebagai ruang interaksi sosial terhadap lingkungan permukiman tersebut adalah ingin menunjukkan sejauh mana interaksi sosial mempengaruhi kondisi sosial masyarakat dan kondisi fisik jalan. Jika hasil penelitian menunjukkan bahwa berbagai aktivitas masyarakat masih memberikan pengaruh yang baik pada lingkungan, berarti ada aspek sosial yang menjadi ciri khas wilayah studi dan memiliki kesamaan kasus di beberapa negara Asia.

\section{Metode Penelitian}

Metode penelitian yang digunakan adalah penelitian kuantitatif dengan strategi penelitian survei. Strategi penelitian survei berusaha memaparkan secara kuantitatif kecenderungan sikap atau opini dari suatu populasi tertentu dengan meneliti satu sampel dari populasi tersebut. Teknik pengumpulan data meliputi survei data primer dan survei data sekunder yang di dalamnya terdapat beberapa metode yang mendukung perolehan data tersebut. Metode survei data primer dilakukan dengan cara observasi, kuesioner, dan wawancara.

Sampel dalam penelitian ini didapat dengan teknik sampling, yakni menentukan jumlah dan ukuran populasi (1.409 KK) kemudian dilakukan perhitungan sehingga didapat ukuran sampel sebanyak 93. Ukuran tersebut menjadi acuan dalam mengumpulkan data melalui kuesioner. Pemilihan sampel dilakukan dengan simple random sampling pada 10 ruas jalan (Gambar 1), yang menjadi target adalah masyarakat yang sedang beinteraksi sosial di jalan lingkungan dan gang. Metode analisis yang digunakan dalam penelitian ini adalah metode statistik deskriptif. Berikut adalah variabel yang digunakan dalam penelitian ini:

Tabel 1. Variabel Penelitian

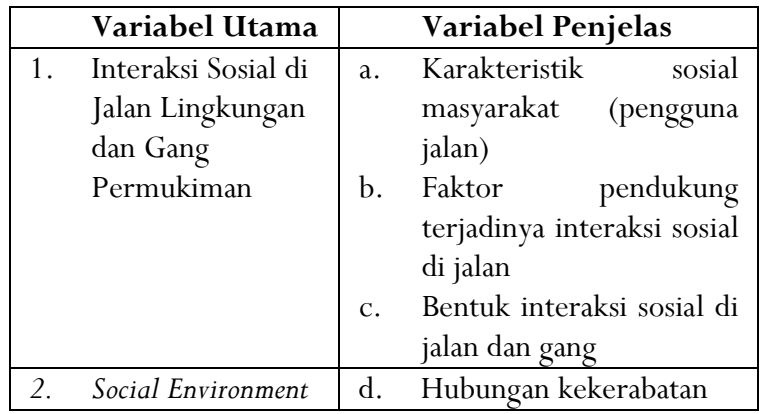




\begin{tabular}{|ll|ll|}
\hline & Variabel Utama & & Variabel Penjelas \\
\hline & & e. & Konflik antar masyarakat \\
\hline 3. & $\begin{array}{l}\text { Neighborhood } \\
\text { Environment }\end{array}$ & f. & $\begin{array}{l}\text { Kondisi fisik jaringan } \\
\text { jalan permukiman }\end{array}$ \\
& g. & $\begin{array}{l}\text { Kebersihan jalan dan } \\
\text { drainase }\end{array}$ \\
\hline
\end{tabular}

Sumber: Penulis, 2011

\section{LITERATUR INTERAKSI SOSIAL DAN JALAN Permukiman}

- Interaksi Sosial

Interaksi sosial merupakan hubunganhubungan yang dinamis menyangkut hubungan antar orang, antar kelompok, maupun antar individu dengan kelompok manusia (Gillin dalam Waluyo, 2008:43). Tidak selamanya interaksi sosial berupa tindakan yang bersifat kerjasama, contohnya adalah tindakan pertengkaran yang termasuk interaksi sosial. Hal ini karena keduanya melakukan hubungan timbal balik walaupun dalam bentuk pertikaian. Gillin (dalam Soekanto, 2006) membedakan bentuk interaksi sosial ada dua macam yaitu asosiatif (menguatkan ikatan sosial, bersifat mendekatkan atau positif) dan disosiatif (merusak ikatan sosial, bersifat negatif).

Ruang publik sebagai ruang interaksi sosial merupakan ruang bersama suatu komunitas yang di dalamnya terdapat aktifitas sosial kemasyarakatan secara rutin/ setiap hari dan aktifitas ketika ada event tertentu (Carr, et al,1992:11). Ruang publik dapat berbentuk cluster maupun linier dalam ruang terbuka maupun tertutup. Carr et al (1992:79-84) menjelaskan tipologi/ bentuk kontemporer dari suatu ruang publik perkotaan yaitu taman-taman publik, lapangan dan plasa, tempat peringatan, pasar, jalan (pedestrian ways, pedestrian mall, jalur lambat, gang/ jalan kecil), lapangan bermain anak, ruang terbuka untuk masyarakat, jalur hijau, atrium/ pasar tertutup, dan ruang di lingkungan bertetangga.

\section{- Jaringan Jalan Permukiman}

Jalan perumahan merupakan salah satu struktur penting dari dalam suatu sistem jaringan jalan perkotaan. Sehingga, peranan jalan ini jika berfungsi dengan baik dapat menentukan kualitas sebuah kota, serta memberikan kenyamanan dan kesejahteraan bagi warganya (SNI 03-6967-2003 Persyaratan umum sistem jaringan dan geometrik jalan perumahan).

Michael Southworth \& Eran ben - Joseph (1996:6-7) menjelaskan bahwa jalan-jalan di lingkungan permukiman tidak hanya berfungsi sebagai akses kendaraan, tetapi sebagai tempat aktivitas sosial termasuk tempat bermain anak dan tempat rekreasi. J.B. Jackson (dalam Girling dan Helpband, 1994:34) menjelaskan pengertian jalan adalah koridor sirkulasi, tempat orang berjalan, ruang sosial, dan ruang terbuka utama untuk rekreasi. Lynch (1991:306) berpendapat bahwa jalan jalan juga dapat berfungsi sebagai identitas yang mencerminkan karakter dari suatu tempat dan menjadi tempat yang bisa dikenang/ tak terlupakan.

\section{- Lesson Learn Jalan Permukiman}

Jalan dan trotoar memiliki arti khusus di Asia, karena kehidupan sehari-hari (pagi sampai larut malam) berlangsung di jalan yang ramai oleh ikatan sosial yang dibentuk di sisi jalan. Banyak fenomenafenomena yang tidak terduga di negara barat namun terjadi di negara-negara di Asia. Hal seperti inilah yang menjadi dasar untuk menyelenggarakan Great Asian Streets Symposium (GASS) pada tahun 2001.

Karakteristik jalan di Sri Lanka yakni jalan didekorasi untuk sebuah acara keagamaan, acara pemakaman, dan juga jalan dipergunakan sebagai pasar (Dayaratne dalam Kiang et al, 2010:63-73). Sedangkan Malaysia menerapkan prinsip multidimensi yaitu jalan multifungsi, multi kelas, multi agama, dan multi ras. Jalan multifungsi di Malaysia adalah jalan yang dipergunakan untuk berbagai aktivitas yaitu sebagai pasar, tempat penyelenggaraan festival dan aktivitas sehari-hari masyarakat (Utaka dan Fawzi dalam Kiang et al, 2010:79-85). Permukiman di Sampaloc memiliki karakteristik jalan yang sempit, sehingga jalan sebagai utilitas umum dipergunakan sebagai tempat untuk bekerja (jasa cuci baju), tempat menjemur pakaian, dan tempat bermain anak (Dela Paz dalam Kiang et al, 2010:93-102).

- Lingkungan Permukiman

Permukiman merupakan wadah fisik (perumahan) beserta sarana prasarana penunjangnya dan merupakan perpaduan antara wadah dan isinya yakni manusia yang hidup bermasyarakat dengan unsur budaya dan lingkungannya (Sudharto, 2005:104). Permukiman terbentuk atas kesatuan antara manusia dan lingkungan di sekitarnya. Permukiman terdiri dari dua bagian yaitu manusia (baik sebagai pribadi maupun dalam hubungan sosial) dan tempat yang mewadahi manusia berupa bangunan (baik rumah maupun elemen penunjang lain). Menurut Costantinos A. Doxiadis (1968), terdapat lima elemen dasar permukiman, yakni alam (nature), manusia (antropos), masyarakat (society), ruang kehidupan (shell), dan jaringan atau sarana prasarana (networks).

Berkaitan dengan masalah penelitian yaitu jalan digunakan masyarakat sebagai ruang interaksi sosial, maka elemen lingkungan permukiman yang berkaitan secara langsung adalah masyarakat dan jaringan. Masyarakat merupakan kesatuan kelompok orang (keluarga) dalam suatu permukiman yang membentuk suatu komunitas tertentu. Penilaian terhadap kondisi sosial masyarakat dimaksudkan 
untuk mengetahui tingkat kekerabatan masyarakat dan permasalahan yang ditimbulkan dari kegiatan masyarakat di jalan dan gang. Penilaian terhadap jaringan yaitu penilaian terhadap kondisi fisik jalan dan sekitarnya (drainase dan kebersihan lingkungan). Kedua penilaian tersebut dilakukan untuk memperlihatkan pengaruh yang telah diberikan dari berbagai macam kegiatan di jalan dan gang permukiman.

\section{Jalan Permukiman Sebagai Ruang INTERAKSI SOSIAL DI KELURAHAN BUNGUR}

Wilayah studi penelitian ini adalah Kelurahan Bungur, yang terletak di Kecamatan
Senen, Kota Administrasi Jakarta Pusat. Kelurahan ini memiliki luas wilayah 69,96 Ha dan secara administratif terbagi menjadi $10 \mathrm{RW}$ dan $130 \mathrm{RT}$. Jumlah penduduk Kelurahan Bungur yaitu 16.204 jiwa (Desember 2010) dan memiliki kepadatan penduduk bruto sekitar 232 jiwa/ha. Kepadatan penduduk di Kelurahan Bungur termasuk dalam kategori kepadatan tinggi (antara 201-400 jiwa/Ha) dan termasuk paling padat di antara kelurahan lain di Kecamatan Senen. Adapun wilayah amatan penelitian adalah RW.01, RW.02, dan RW.03. Hal ini didasari oleh banyak jalan dan gang yang digunakan untuk aktivitas masyarakat pada ketiga RW tersebut.

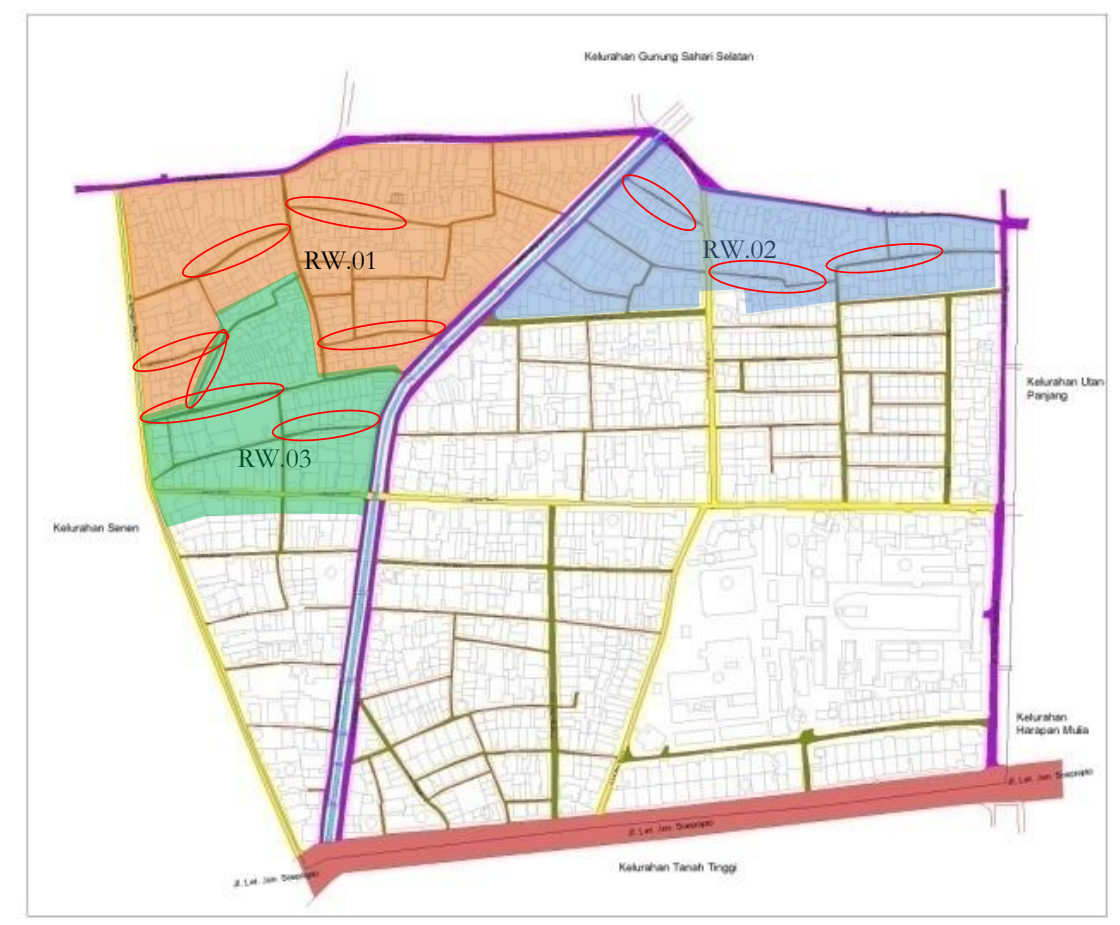

Sumber: Dinas Tata Ruang dan Pertanahan Kota Jakarta

\section{Gambar 1. Lokasi Penelitian, Kelurahan Bungur}

- Karakteristik Sosial Masyarakat

Masyarakat yang dimaksud pada analisis karakteristik sosial adalah masyarakat yang menggunakan jalan dan gang sebagai ruang untuk beraktivitas, baik itu aktivitas yang menimbulkan interaksi sosial maupun aktivitas yang bersifat pasif. Pengguna jalan lingkungan dan gang bisa dikelompokkan menjadi ibu-ibu, bapak-bapak, remaja, dan anak-anak. Berdasarkan hasil observasi, keinginan berinteraksi sosial di lingkungan permukiman Bungur lebih banyak berasal dari kaum perempuan (71\%). Ibu-ibu lebih sering berkumpul untuk sekedar mengobrol atau meminta pendapat, beda halnya dengan bapak-bapak yang bekerja setiap hari dan hanya pada waktu-waktu tertentu saja bisa berkumpul dengan warga sekitar lingkungan permukiman.

Penduduk yang sudah lebih dari 30 tahun tinggal di Kelurahan Bungur adalah pengguna yang paling sering terlihat di jalan lingkungan. Mereka 
adalah ibu-ibu yang memiliki banyak waktu luang karena sudah tidak sibuk dalam mengasuh anak dan pekerjaan rumah tangga lainnya. Jumlah penduduk Kelurahan Bungur berdasarkan struktur pendidikan tahun 2010 lebih didominasi oleh penduduk dengan tamatan SMA kemudian diikuti oleh tamatan SMP dan SD. Latar belakang pendidikan masyarakat yang menggunakan jalan adalah tamatan SMA dan SMP. Hal ini mengindikasikan bahwa masyarakat yang menggunakan jalan sebagai ruang interaksi sosial serta untuk aktivitas pribadi miliki tingkat pendidikan yang cukup bukan pendidikan yang rendah.

Karakteristik masyarakat berdasarkan mata pencaharian di Kelurahan Bungur lebih didominasi oleh perkerjaan sebagai wiraswasta (termasuk tukang ojek, pedagang kaki lima, pedagang warung, dan pedagang toko). Karakteristik pengguna jalan permukiman sebagian besar adalah wanita, yaitu ibuibu yang sehari-harinya bekerja sebagai ibu rumah tangga (IRT) dan juga berjualan di warung. Berdasarkan hasil wawancara kepada kepala Lurah Bungur dan kepala RT, khususnya untuk RW 01 03, tingkat perekonomiannya termasuk golongan menengah ke bawah. Jadi pada wilayah tersebut masih terdapat keluarga pra sejahtera yang masih memerlukan subsidi pemerintah.

- Alasan Masyarakat menggunakan jalan sebagai ruang interaksi sosial

Penggunaan jalan sebagai ruang interaksi sosial di Kelurahan Bungur lebih disebabkan oleh keinginan masyarakat untuk melakukan aktivitas dekat dari rumah padahal di sekitar rumah tidak terdapat taman/ lapangan/ lahan kosong (kasus pada RW.01, RW.02, dan RW.03). Sedangkan di Negara Malaysia, jalan dapat menjadi ruang aktivitas masyarakat dipengaruhi oleh perbedaan ras yang kemudian mempengaruhi desain jalan tersebut. Kasus di Sampaloc, Manila, jalan menjadi tempat yang sesuai untuk aktivitas karena dipengaruhi oleh faktor ekonomi.

Sebagian besar alasan masyarakat menggunakan jalan dan gang karena dekat dari rumah (61\%). Seperti untuk jualan, mereka tidak mungkin mengambil lahan di wilayah lain yang jauh dengan rumahnya. Kedekatan dengan rumah akan mempermudah dalam membawa bahan-bahan makanan dan peralatan masak yang digunakan. Selain itu, warga mengobrol dengan sesama tetangga lebih nyaman di wilayah sendiri, yakni dekat rumah agar tidak menimbulkan buruk sangka dari warga lain. Kesimpulannya adalah bila beraktivitas di dekat rumah atau dalam wilayah/RT sendiri lebih aman ketimbang ditempat lain.

\section{- Bentuk Interaksi Sosial}

Bentuk interaksi sosial di jalan lingkungan yang bersifat menguatkan ikatan sosial adalah aktivitas tegur sapa, mengobrol, jual beli, bermain, arisan, gotong royong, senam, acara pernikahan, dan festival tahunan. Sedangkan bentuk kegiatan yang bersifat merusak ikatan sosial yaitu tawuran anakanak kecil (sekolah dasar) pada malam hari.

Aktivitas tegur sapa, mengobrol, bermain, dan aktivitas jual beli dapat bersifat interaksi sosial tanpa perencanaan karena aktivitas tersebut terjadi secara alamiah dan berulang secara terus-menerus. Interaksi sosial yang paling jarang terjadi adalah interaksi sosial yang bersifat tiba-tiba, karena bersifat kondisional tidak setiap waktu terjadi dan tidak tahu kapan akan terjadi, contohnya adalah seseorang yang bertanya alamat pada warga yang duduk di pinggir jalan.

Dari sekian banyak kegiatan yang dilakukan masyarakat di jalan lingkungan dan gang, perlu diketahui jenis aktivitas yang dominan. Aktivitas masyarakat yang paling dominan terjadi di jalan permukiman adalah aktivitas bersantai (digunakan untuk mengobrol dengan sesama warga, dudukduduk untuk melepas lelah, menonton tv, bermain catur, dll). Pada ruas jalan dan gang lingkungan permukiman disediakan kursi atau dibuat bangku bangku panjang tempat masyarakat mengobrol. Jadi, dalam satu ruas jalan, akan ramai pada beberapa spot, yaitu di bangku-bangku yang telah disediakan atau di warung-warung yang dibuat warga dengan memanfaatkan pinggiran jalan.

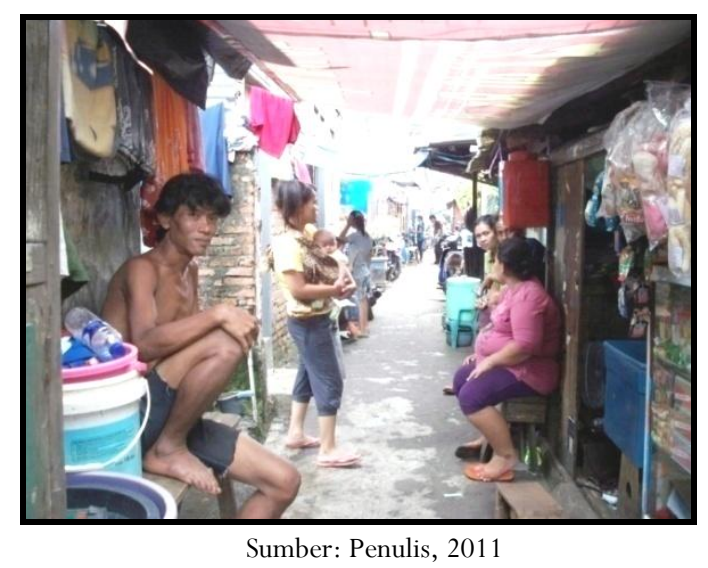

Gambar 2. Aktivitas Bersantai Masyarakat di Gang Kalibaru Timur XIII

Aktivitas masyarakat kedua terbanyak adalah aktivitas jual beli (18\%). Di setiap ruas jalan dan gang lingkungan permukiman Kelurahan Bungur pasti memiliki warung/ tempat jualan yang didirikan dengan mengambil sebagian badan jalan tersebut. Warung-warung tersebut menjual makanan kecil 
dan juga makanan besar untuk sarapan/ makan siang. Sehingga pada pagi hari dan sore hari, jalan dan gang menjadi ramai oleh masyarakat yang membeli makanan dan juga makan ditempat.

Selain itu, jalan di lingkungan permukiman Bungur juga berfungsi sebagai ruang bagi masyarakat untuk aktivitas parkir kendaraan, aktivitas memasak, penyimpanan barang, aktivitas mencuci dan menjemur pakaian.

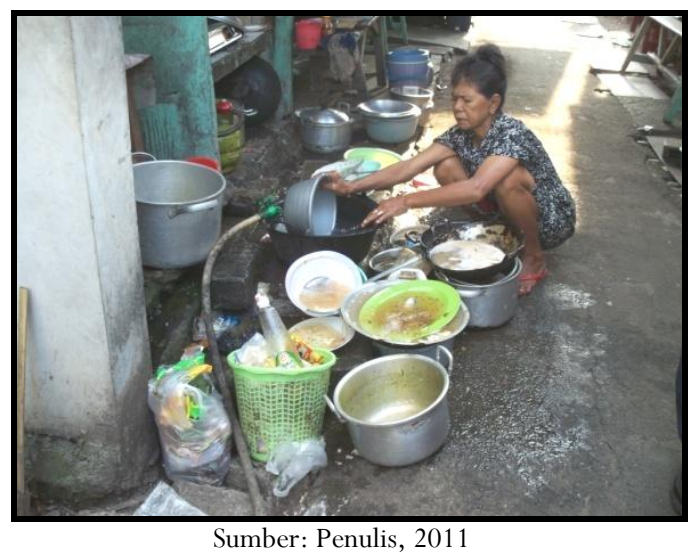

\section{Gambar 3. Aktivitas Mencuci di Ruas Gang Bungur Besar VIIIC}

Jalan lingkungan dan gang permukiman tidak setiap waktu ramai oleh interaksi sosial masyarakat dan terdapat beberapa aktivitas masyarakat yang diadakan rutin pada waktu-waktu tertentu. Ketika Event perayaan hari kemerdekaan jalan dan gang akan sangat ramai oleh kegiatan lomba dan festival. Berdasarkan bentuk kegiatan yang telah dijelaskan sebelumnya, maka kegiatan tersebut dapat dikelompokkan berdasarkan waktu, yaitu aktivitas harian, aktivitas bulanan, aktivitas tahunan, dan aktivitas pada waktu-waktu tertentu. Waktu yang dipilih masyarakat untuk beraktivitas setiap hari adalah sebagai berikut:

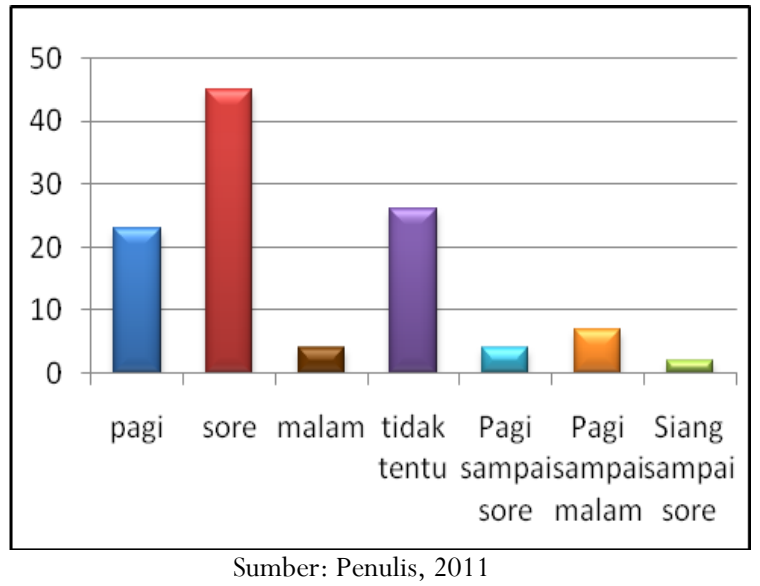

Gambar 4. Grafik Waktu Aktivitas Harian Masyarakat di Jalan Lingkungan dan Gang
- Pengaruh Interaksi Sosial terhadap Lingkungan Sosial dan Fisik Kelurahan Bungur

Interaksi sosial di jalan dan gang seperti tegur sapa, mengobrol, dan jual beli, tanpa sadar telah memberikan pengaruh yang baik terhadap kehidupan sosial masyarakat Kelurahan Bungur. Kekerabatan semakin erat karena antar masyarakat bisa saling berinteraksi. Mereka tidak mencirikan suatu permukiman perkotaan yang kaku dan "cuek," namun menggambarkan suatu permukiman pedesaan yang bisa mengenal semua tetangganya sehingga hubungan kekerabatan masyarakat sangat baik.

Sejauh ini, interaksi sosial yang dilakukan warga Kelurahan Bungur di jalan lingkungan dan gang tidak mengganggu warga sekitar (98\%). Hanya sedikit warga yang merasa terganggu oleh kegiatan tersebut, yaitu mereka merasa kebisingan oleh ramainya aktivitas. Aspek tenggang rasa/ toleransi antar masyarakat menjadi peredam konflik yang dapat timbul dari kegiatan masyarakat di jalan.

Kegiatan mayarakat di jalan lingkungan dan gang juga mempengaruhi bentuk streetscape, setiap jalan/gang yang digunakan sebagai ruang interaksi sosial dicirikan oleh adanya bangku, tenda, pot tanaman, banyaknya motor di pinggir jalan, pakaian yang dijemur, warung, dan alat pembatas kecepatan (polisi tidur/ speed bump). Gangguan sesaat dapat terjadi ketika di satu jalan lingkungan terdapat on street parking yang tidak rapi sehingga mobil yang melintas mengalami kesulitan untuk melewati jalan tersebut.

Arus lalu lintas di jalan lingkungan dan gang masih lancar, interaksi sosial yang dilakukan warga tidak sampai membuat kemacetan. Warga memilih beraktivitas di pinggir jalan lingkungan dan gang, sedangkan anak-anak lebih menggunakan badan jalan sebagai area untuk bermain. Untuk mencegah hal-hal yang tidak diinginkan, maka warga membuat alat pembatas kecepatan (speed bump) pada beberapa ruas jalan yang biasa digunakan anak-anak bermain agar kendaraan yang melintas bisa lebih pelan dan hati-hati.

Kelurahan Bungur memiliki pola jalan berbentuk grid, sehingga pengendara memiliki alternatif jalan yang diinginkan untuk mencapai tujuan. Pengendara motor/mobil tentu saja merasa terganggu jika jalan yang dilewatinya banyak hambatan sampingnya, oleh karena itu kebanyakan dari mereka lebih banyak melewati jalan lingkungan yang lebih sedikit kegiatan masyarakatnya. Hal ini terlihat dari volume lalu lintas di jalan lingkungan pada peak hour bisa mencapai 31-51 motor/10 menit, sedangkan volume lalu lintas di gang 7 motor/10 menit. Gang lebih banyak dipilih oleh pejalan kaki karena tidak banyak kendaraan yang 
melintas, jumlah pejalan kaki di gang pada peak hour bisa mencapai 30 orang/10 menit.

Selain dikaji terhadap fisik jalan, interaksi sosial yang terjadi juga perlu dikaji terhadap aspek kebersihan. Hal ini dikarenakan kemungkinan masalah sampah yang terjadi ketika masyarakat makan dan minum di pinggir jalan. Aspek kebersihan yang diidentifikasi adalah kondisi kebersihan jalan dan gang dan kondisi saluran drainase.

Kondisi lingkungan permukiman Kelurahan Bungur cukup bersih jika dilihat dari kebersihan jalan dan gang, namun bermasalah pada kebersihan saluran drainase yakni banyak sampah dan airnya menggenang. Sejauh ini, kebersihan jalan dan gang permukiman Bungur tidak bermasalah karena semua warga telah sadar akan pentingnya kebersihan dan bahayanya jika membuang sampah sembarangan. Selama mereka berada di melakukan aktivitas di pinggir jalan dan gang tidak membuang sampah sembarangan.

\section{KESIMPULAN}

Jalan pada lingkungan permukiman Bungur tidak hanya sebagai ruang sirkulasi tetapi juga dapat menjadi ruang yang digunakan masyarakat untuk berbagai aktivitas sehari-hari. Interaksi sosial yang tercipta dari aktivitas yang dilakukan masyarakat merupakan hal yang positif dan memberikan pengaruh yang baik pada lingkungan permukiman di Kelurahan Bungur. Kekerabatan yang kuat dan adanya toleransi menjadi salah satu aspek yang membuat aktivitas masyarakat di jalan lingkungan dan gang berjalan dengan baik. Adanya kesamaan aktivitas yang terjadi di jalan permukiman Kelurahan Bungur dan negara-negara Asia lainnya, menunjukkan ciri khas jalan yang membedakan dengan jalan di negara barat seperti yang telah dikemukakan para ahli saat akan menyelenggarakan Great Asian Street Symposium (GASS) pertama kali pada tahun 2001 di Singapura.

Rekomendasi yang ditawarkan dari temuan penelitian di lapangan diharapkan akan bermanfaat bagi masyarakat. Pemerintah dapat menyediakan ruang public yang layak untuk warga, sehingga halhal yang bersifat mengganggu kepentingan umum tidak dibiarkan begitu saja dan jalan tidak menjadi ruang interaksi utama bagi masyarakat. Selain itu, Warga Kelurahan Bungur bisa memperindah tampilan streetscape yang ada di pinggir jalan dengan menambah nilai estetika kelurahan tersebut. RW.03 yang merupakan kawasan binaan Kelurahan Bungur, bisa menjadi contoh bagi RW-RW lain.

\section{DAfTAR Pustaka}

Carr, Stephen et al. 1992. Public Space. United States of America: Cambridge University Press.

Dimitriou, Harry T. 1995. A Development Approach to Urban Transport Planning: An Indonesian Illustration. Aldershoot: Avebury.

Doxiadis, Constantinos A. 1968, An Introduction To The Science of Human Settlements-Ekistics, London: Hutchinson of London.

Girling, Cynthia L dan Kenneth I. Helpband. 1994. Yard Street Park. America: John Wiley \& Sons, Inc.

Kiang, Heng Chye et al. 2010. On Asian Streets and Public Space. Singapore: Mainland Press Pte Ltd.

Koppelman, Lee.e and De Chiara, Joseph. 1997. Site Planning Standar. Cetakan keempat. Terjemahan Januar Hakim. Jakarta: Erlangga.

Lynch, Kevin. 1991. City Sense and City Design. Second Printing. Edited by: Banerje and Southworth. Cambridge: MIT Press.

Majumder, Ahmad Kamruzzaman. 2007. "Urban Environmental Quality Mapping : A Perception Study On Chittagong Metropolitan City." Journal of Science Engineering and Technology, Vol.I, No. IV, 1-14.

Potterfield, Gerald A dan Hall, Kenneth B. 1995. A Concise Guide to Community Planning. New York: McGraw-Hill,Inc.

Soekanto, Soerjono. 2006. Sosiologi Suatu Pengatar. Jakarta:Rajagrafindo Persada.

Soemarwoto, Otto. 1989. Analisis Dampak Lingkungan. Yogyakarta: Gadjah Mada University Press.

Southworth, Michael and Eran Ben-Joseph. 1996. Street and The Shaping of Town and Cities. United States of America: MCGraw-Hill Companies

Waluyo, et al. 2008. Ilmu Pengetahuan Sosial. Jakarta: Pusat Perbukuan, Departemen Pendidikan Nasional. 